\title{
Experimental Study on Influence of Electropulsing to Microstructural Evolution of Billet
}

\author{
Zheng-hai Zhu ${ }^{\mathrm{a}}$, Wang Jian-jun ${ }^{\mathrm{b}}$, Zhou Lic \\ College of Metallurgy and Resources,Anhui University of Technology, MaanshanAnhui , China; \\ azhu_zhenghai@163.com, bwang-jj@ahut.edu.cn, 'chouli@ahut.edu.cn
}

Keywords: billet; microstructural evolution; electropulsing; nucleation;ferrite

\begin{abstract}
This paper studies the influence to the microstructural evolution of low carbon steel and low carbon $\mathrm{Nb}$ steel through experiments in order to improve the microstructure of billet. The results of the study show that electropulsing has significant impact on the phase transformation from austenite to ferrite of low carbon steel and low carbon $\mathrm{Nb}$ steel, which improves nucleation rate of ferrite inside austenite grain. And it also shows that electropulsing promotes the nucleation and precipitation of $\mathrm{NbCN}$ in low carbon $\mathrm{Nb}$ steel and a large number of $\mathrm{NbCN}$ particles provide the nucleation sites for austenitic $\rightarrow$ ferritic phase transformation, which improves nucleation rate of ferrite inside austenite grain. The improvement of nucleation rate of ferrite inside austenite grain effectively restrains the formation of pro-eutectoid ferrite omentum at austenitic grain boundaries.
\end{abstract}

\section{Introduction}

Electropulsing treatment, serving as a kind of newly-emerged material handling and preparation method, possesses such features as fast heating, composite electromagnetic force, reduced thermokinetics potential barrier, high-speed electron impact and so on. When acting on materials, the magnetism, heat, and strength effect generated by electropulsing treatment all have special impact on the material composition, structural state and atom diffusion inside material ${ }^{[1]}$.

For the past few years, some scholars both at home and abroad have attempted to improve the structure of solid phase metallic material under the action of electropulsing, and obtained some achievements. The findings of Conrad. $\mathrm{H}^{[2]}$ reveal that electropulsing has significant impact on the precipitation behavior of precipitated phase in solid state metal, and the major influencing factors include material type, current density and power frequency. Yang Liu considers ${ }^{[3]}$ that electropulsing is influential to carbide precipitation in GH3044 alloy, impulse treatment has changed thermodynamics and dynamical condition of carbide precipitation, and the selection of proper impulse parameters is beneficial to carbide precipitation, manifesting by the decrease of starting precipitation temperature and increase of overall amount of precipitated phase. In Malard $\mathrm{B}^{[4]}$ 's study on NiTi alloy wire cold drawing structure and Qin, R. $S^{[5]}$ 's study on carbide in pearlitic steel wire, it is revealed that current impulse treatment can influence the structure evolution of solid state metallic material, and the selection of certain electropulsing parameters can improve the material performances. The researches made by Samuel ${ }^{[6]}$. Tanaka $S^{[7]}$, He Lijia ${ }^{[8]}$ et al reveal that electropulsing can accelerate the atom diffusion in solid state metal. The researches of $\mathrm{Li}$ Qingchun ${ }^{[9,10]}$ reveal that electropulsing can strengthen the diffusing capacity of carbon atom in $\gamma$ phase, reduce the nucleation potential barrier of graphite, and increase the nucleation rate of

graphite. It is revealed in $\mathrm{Yu}$ Wenpeng ${ }^{[11]}$, s researches that current impulse can reduce the nucleation potential barrier of $\alpha$ phase, and enhance the nucleation rate of $\alpha$ phase. It is revealed in Liu,W.B ${ }^{[12]}$, s study on memory alloy FeMnSiCrNiNbC that electropulsing treatment can enable the precipitation speed of $\mathrm{NbC}$ in alloy to be quicker, the amount of precipitated particle to be even more, and grains to be even smaller. It is revealed in Wang Jianjun ${ }^{[13]}$ 's study that electropulsing treatment can enhance the isometric crystal nucleation rate, which represents significant effect in the process of improving solidification structure of continuous casting billet.

However, until now, there are few researchers have applied electropulsing treatment in the process of improving microscopic structure of continuous casting billet in metallurgical process. 
The author, based upon the researches of predecessors, applies electropulsing treatment in continuous casting billet, and studies its impact on the microscopic structure evolution of continuous casting billet, providing theoretical basis for improving mechanical properties, reducing the defect, and improving the quality ${ }^{[14 \sim 15]}$.

\section{Test materials and methods}

\subsection{Test materials}

Two steel grades with similar composition are selected as test materials, and they are respectively indicated as $\mathrm{E}$ and $\mathrm{F}$, as shown in Figure 1. The difference between these two steel grades lie in that $\mathrm{E}$ is ordinary low carbon steel, $\mathrm{F}$ is low carbon $\mathrm{Nb}$-containing micro-alloyed steel.

Table 1 Chemical composition of tested steel

\begin{tabular}{cccccccccccc}
\hline Content(\%) & $\mathrm{C}$ & $\mathrm{Si}$ & $\mathrm{Mn}$ & $\mathrm{P}$ & $\mathrm{S}$ & $\mathrm{Als}$ & $\mathrm{Nb}$ & $\mathrm{N}$ & $\mathrm{Ni}$ & $\mathrm{Cr}$ & $\mathrm{Cu}$ \\
\hline Steel E & 0.102 & 0.383 & 1.398 & 0.019 & 0.007 & 0.031 & & 0.0055 & 0.007 & 0.015 & 0.020 \\
Steel F & 0.099 & 0.181 & 1.339 & 0.011 & 0.003 & 0.025 & 0.024 & 0.0048 & 0.008 & 0.013 & 0.023 \\
\hline
\end{tabular}

\subsection{Test methods}

The test process is shown as follows, first of all, apply intermediate frequency vacuum induction furnace to smelt, cast and obtain billets with two kinds of compositions, namely, E and F. Next, cut the billets into small test pieces, connect to impulsing power source device through lead wire, and then put the test pieces into box-type electric resistance furnace. After heat preservation for $1 \mathrm{~h}$ at $1200^{\circ} \mathrm{C}$, cool down to $750^{\circ} \mathrm{C}$ at the rate of $6^{\circ} \mathrm{C} / \mathrm{min}$, take out test pieces, and quench in water solution containing $10 \%$ concentration of $\mathrm{NaCl}$. The test is divided into two groups, and each group contains two test pieces ( $\mathrm{E}$ and $\mathrm{F}$ ), one group is arranged without electropulsing treatment, and the other group is arranged with electropulsing treatment. The current is $60 \mathrm{~A}$, frequency is $30 \mathrm{~Hz}$, as shown in Figure 2. After cutting, planishing, and polishing of obtained test pieces, use 5\% nitric acid alcohol to erode, and observe the microscopic structure with metallurgical microscope. TEM sample is prepared by using carbon film extraction replica method.

Table 2 Explain of sample

\begin{tabular}{|c|c|c|c|}
\hline & Sample & Steel Grade & $\begin{array}{c}\text { Electropulsing } \\
\text { treatment }\end{array}$ \\
\hline \multirow{2}{*}{ Group 1 } & E1 & Low carbon steel & No \\
\cline { 2 - 4 } & F1 & Low carbon Nb steel & No \\
\hline \multirow{2}{*}{ Group 2 } & E2 & Low carbon steel & Yes \\
\cline { 2 - 4 } & F2 & Low carbon Nb steel & Yes \\
\hline
\end{tabular}

The temperature value corresponding to the equilibrium phase transition point of sample, Ae1 and Ae3, can be obtained through the calculation ${ }^{[14]}$ by applying equation (1) and (2). Ae1 and Ae3 corresponding to steel grade $\mathrm{E}$ are $712^{\circ} \mathrm{C}$ and $826^{\circ} \mathrm{C}$, respectively. Ael and Ae3 corresponding to steel grade $\mathrm{F}$ are $708^{\circ} \mathrm{C}$ and $854^{\circ} \mathrm{C}$, respectively.

$$
\begin{aligned}
& \text { Ael }=722.8-13.9[\% \mathrm{Mn}]+22.2[\% \mathrm{Si}]+23.3[\% \mathrm{Cr}]-14.4[\% \mathrm{Ni}] \\
& \text { Ae3 }=854.4-179.4[\% \mathrm{C}]-13.9[\% \mathrm{Mn}]+44.4[\% \mathrm{Si}]-1.7[\% \mathrm{Cr}]-17.8[\% \mathrm{Ni}]
\end{aligned}
$$

\section{Analysis and discussions}

2.1 Impact of electropulsing on structural evolution of low carbon steel

As Ael and Ae 3 corresponding to steel grade $\mathrm{E}$ are $712^{\circ} \mathrm{C}$ and $826^{\circ} \mathrm{C}$, respectively, $750^{\circ} \mathrm{C}$ is just within two phase zones. At this moment, the microscopic structure should be austenite and ferrite. After sample treatment, the microstructure is as shown in Figure 1. It can be seen in this figure that white pro-eutectoid ferrite forms in austenite grain boundary when there is no electropulsing treatment, and exists in film-like shape. There is no ferrite inside austenite grain. White pro-eutectoid ferrite still exists in austenite grain boundary when there is electropulsing treatment, and also exists in film-like shape except that the film thickness becomes thin dramatically. In addition, the ferrite edge on austenite grain boundary is not smooth. Instead, it is serrated and has 
the indication extending to the inside of austenite grain. Moreover, there is also a small amount of ferrite inside the austenite grain. The comparisons between these two scenarios reveal that electropulsing has significant influence on the microscopic structure phase transition of $\mathrm{E}$ billet, and change the nucleation site of some pro-eutectoid ferrites under similar heat treatment condition. When there is no electropulsing treatment, along with the temperature declines until below Ae3 point, since that austenite grain boundary possesses major interfacial energy and quicker diffusion rate, ferrite has priority to form nucleation hereon, and continuously precipitate along austenite grain boundary. However, it fails to possess priority even though there is extension in thickness. Along with the nucleation and precipitation of pro-eutectoid ferrite at different positions of austenite grain boundary, film-like pro-eutectoid ferrite finally forms in austenite grain boundary. When there is electropulsing treatment, along with the temperature declines until below Ae 3 point, due to the action of electropulsing, pro-eutectoid ferrite not only precipitates in austenite grain boundary, but also begins to nucleate and precipitate inside austenite grain. However, the nucleation in austenite grain boundary is given the first place.

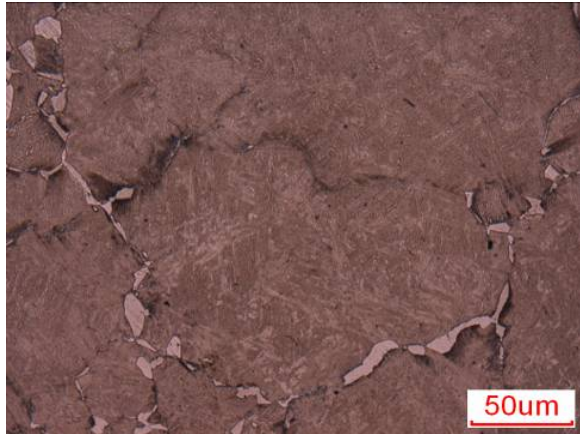

E1 Non electropulsing treatment $\left(750^{\circ} \mathrm{C}\right)$

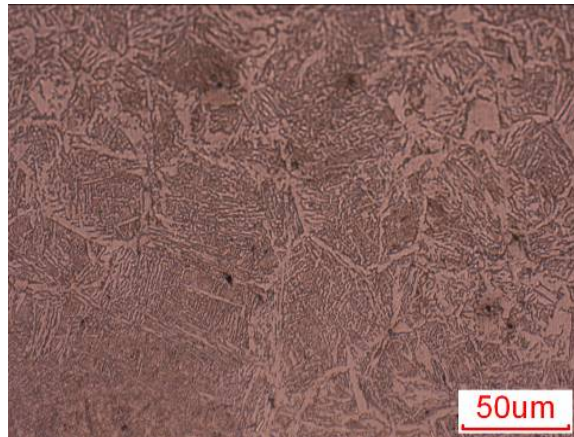

E2 Electropulsing treatment $\left(750^{\circ} \mathrm{C}\right)$

Fig.1 Microstructural of low carbon steel E

2.2 Impact of electropulsing on structural evolution of low carbon niobium-containing steel

As Ae1 and Ae 3 corresponding to steel grade $\mathrm{F}$ are $708^{\circ} \mathrm{C}$ and $854^{\circ} \mathrm{C}$, respectively, $7500^{\circ} \mathrm{C}$ is just within two phase zone. At this moment, the microstructure should be austenite and ferrite. After sample preparation, the microstructure is as shown in Figure 2. It can be seen in this figure that white pro-eutectoid ferrite exists in film-like shape in austenite grain boundary when there is no electropulsing treatment, and there is no ferrite inside austenite grain. When there is electropulsing treatment, there is only small amount of extremely thin white pro-eutectoid ferrite film in some portions of austenite grain boundary, the majority of ferrite precipitate inside austenite grain, and distribute in dispersion manner. The comparisons between these two scenarios reveal that electropulsing has significant influence on the microstructure phase transition of $\mathrm{F}$ billet, and change the nucleation site of most pro-eutectoid ferrites under similar heat treatment condition. When there is no electropulsing treatment, along with the temperature declines until below Ae3 point, for the same reason as that of E billet, ferrite has priority to form nucleation in austenite grain boundary, and forms film-like pro-eutectoid ferrite. Moreover, there is no nucleation point inside austenite grain. When there is electropulsing treatment, along with the temperature declines until below Ae3 point, due to the action of electropulsing, the majority of ferrite precipitates nucleation inside austenite grain, and only a small portion of ferrite nucleates inside austenite grain boundary.
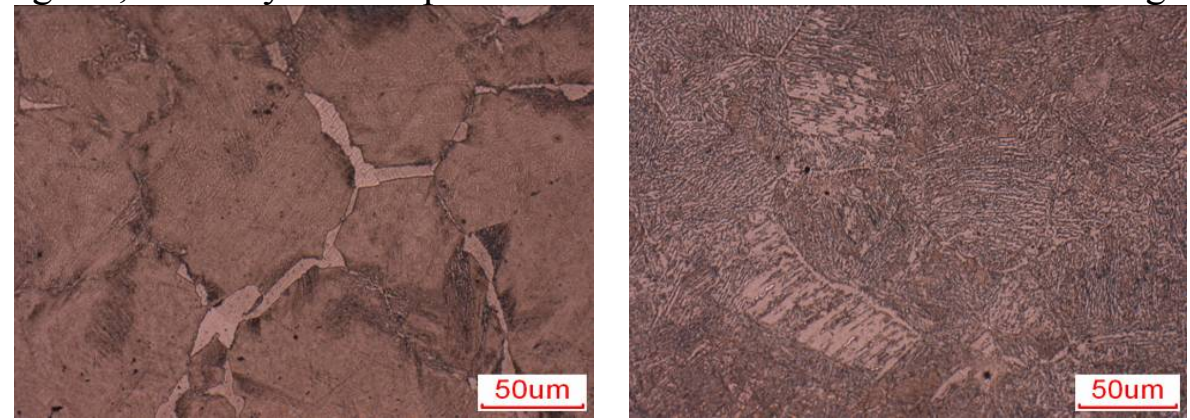

F1 Non electropulsing treatment $\left(750^{\circ} \mathrm{C}\right) \quad$ F2 Electropulsing treatment $\left(750^{\circ} \mathrm{C}\right)$

Fig.2 Microstructural of low carbon $\mathrm{Nb}$ steel $\mathrm{F}$ 
2.3 Differences in the impact of electropulsing on microstructural evolution of different steel grades

It can be known from the above test results that electropulsing treatment has significant impact on the microstructural evolution of low carbon steel $\mathrm{E}$ and low carbon $\mathrm{Nb}$-containing steel $\mathrm{F}$ billet, and effectively changes the nucleation site of ferrite, from pure austenite grain boundary nucleation to simultaneous nucleation both in grain boundary and austenite matrix, however, the differences still exist in the impact of electropulsing treatment on two steel grades. For low carbon E billet, electropulsing treatment can enable ferrite to be simultaneously precipitated both inside austenite matrix and grain boundary. However, there are a large amount of obvious film-like ferrites at austenite grain boundary. This shows that electropulsing has certain influence on phase transition of austenite-ferrite, yet is still not able to restrain the generation of ferrite in austenite grain boundary and formation of film-like shape. For low carbon $\mathrm{Nb}$-containing steel $\mathrm{F}$ billet, electropulsing treatment can equally enable ferrite to be simultaneously precipitated both inside austenite matrix and grain boundary. However, ferrites mainly generate inside austenite grain in dispersion manner, and its manifestation in austenite grain boundary shows that there are still a small amount of unobvious film-like ferrites at partial sites, and the formation of obvious film-like ferrite fails to be observed in the most of visual fields.
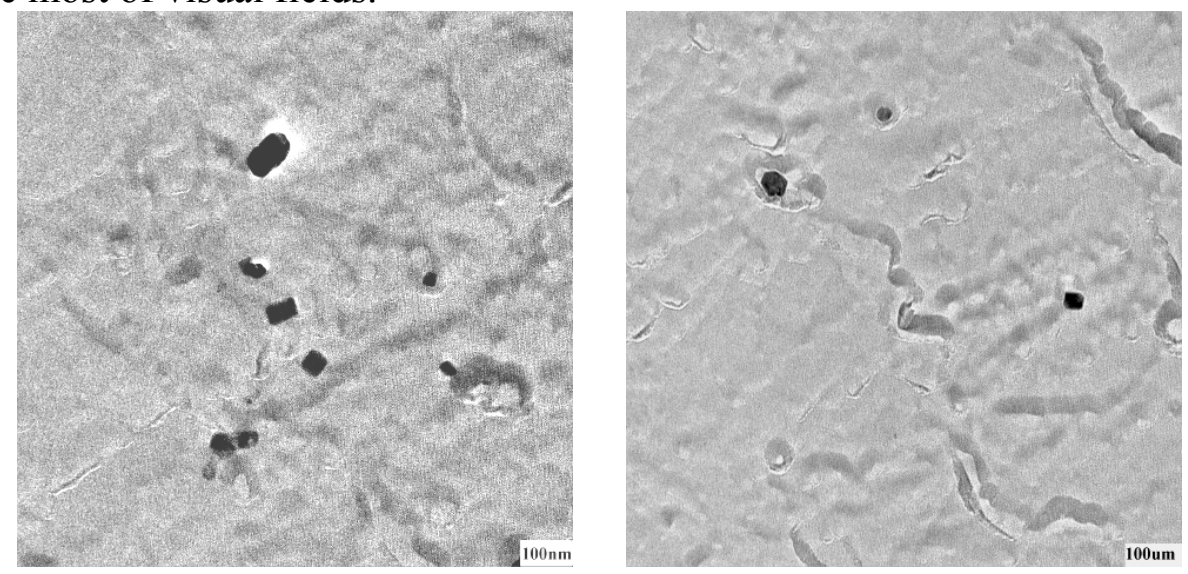

Fig. $3 \mathrm{NbCN}$ in sample of low carbon $\mathrm{Nb}$ steel F2

How come the generation of differences in microstructural evolution of different steel grades under the same heat treatment and pulse treatment condition? Through TEM analysis of E2 and F2 samples, the results are shown in Figure3. It can be known from Figure 3 that many fine carbonitride second-phases distribute in low carbon Nb-containing steel F2, i.e. NbCN particle, which size is $20 \sim 100 \mathrm{~nm}$. However, there are no these particles in low carbon E2. Therefore, through survey ${ }^{[12]}$ and analysis, it can be considered that a large amount of NbCN precipitates in austenite under the action of electropulsing, and becomes nucleation site of ferrite in austenite $\rightarrow$ ferrite phase transition process, which enable the dispersive precipitation of ferrite in austenite, and restrict the formation of film-like ferrite in austenite grain boundary.

The above results indicate that electropulsing has significant impact on austenite $\rightarrow$ ferrite phase transition and $\mathrm{NbCN}$ precipitation behavior. Moreover, $\mathrm{NbCN}$ behavior also has impact on austenite $\rightarrow$ ferrite phase transition.

\subsection{Discussions}

2.3.1 Influence mechanism of electropulsing on austenite $\rightarrow$ ferrite phase transition

The impact of electropulsing treatment on metallic material is more ${ }^{[1]}$. For austenite $\rightarrow$ ferrite phase transition process, its mechanism of action is mainly reflected in the rapid heating and decline of ferrite nucleation potential barrier, and thus improves the nucleation rate of ferrite. Under the condition that there is no electropulsing treatment, due to the relatively smaller interfacial energy than grain boundary, ferrite fails to obtain adequate phase transformation driving force to nucleate inside the austenite grain of low carbon steel $\mathrm{E}$ and low carbon $\mathrm{Nb}$-containing steel $\mathrm{F}$. In case there is electropulsing treatment, on one hand, due to the effective decline of ferrite nucleation potential barrier and decrease of phase transformation driving force, ferrite can be nucleation precipitated at 
some defects of inside austenite grain, and thus improves the nucleation rate of ferrite inside austenite grain. On the other hand, due to the rapid heating action of electropulsing, the ferrite precipitated at austenite grain boundary along with the decline of ambient temperature at the beginning period is once again phase-changed into austenite under the interrupted heating action, and retransformed into ferrite with the decline of ambient temperature. The mass nucleation particles, generated in such repeated transition process, effectively improves the nucleation rate of ferrite, and forms such phenomenon as that the ferrite at E2 sample austenite grain boundary in Figure 1 is serrated relative to E1 sample, and possesses the trend of extending to the inside of austenite grain. It can be discovered in the mircostructure of E2 sample in Figure 1 that the serrated ferrite at austenite grain boundary is relatively developed, indicating that the impact generated by the rapid heating action of electropulsing in low carbon steel $\mathrm{E}$ is comparatively significant.

2.3.2 Influence mechanism of electropulsing on $\mathrm{NbCN}$ precipitation

Prior to electropulsing treatment, it can be seen from the microstructure of E1 in Figure 1 and the microstructure of $\mathrm{F} 1$ in Figure 2 that austenite $\rightarrow$ ferrite phase transition process of low carbon steel $\mathrm{E}$ and low carbon $\mathrm{Nb}$-containing steel $\mathrm{F}$ is basically identical, and all manifested by nucleation precipitation of pro-eutectoid ferrite in austenite grain boundary and formation of film-like shape. However, under the electropulsing treatment condition, it can be seen from the microstructure of E2 in Figure 1 and the microstructure of F2 in Figure 2 that dramatic differences exist in austenite $\rightarrow$ ferrite phase transition processes corresponding to low carbon steel $\mathrm{E}$ and low carbon $\mathrm{Nb}$-containing steel $\mathrm{F}$, mainly manifested by the fact that there is still obvious film-like ferrite in the mircostructure of low carbon steel $\mathrm{E}$ while there is still a small amount of unobvious film-like ferrite in the microstructure of $\mathrm{Nb}$-containing steel $\mathrm{F}$ at austenite grain boundary. The reason for the generation of this difference lies in the fact that $\mathrm{NbCN}$ precipitation behaviors inside $\mathrm{Nb}$-containing steel $\mathrm{F}$ are different depending on whether electropulsing treatment conditions exist or not. When electropulsing treatment does not exist ${ }^{[17]}$, nucleation precipitation of $\mathrm{NbCN}$ slowly happens in steel. After the temperature declines until below Ae3 point, along with the generation of pro-eutectoid ferrite film in austenite grain boundary, due to the obvious decrease of solubility product of $\mathrm{NbCN}$ in ferrite relative to the scenario that occurs in austenite, the rapid precipitation of $\mathrm{NbCN}$ in ferrite film is achieved. When electropulsing treatment exists, since that the precipitation of $\mathrm{NbCN}$ is a process of atom diffusion, nucleation and growth, and the driving force generated by compound electricity effect ${ }^{[18]}$ possessed by electropulsing treatment can not only accelerate the migration of solute atoms and vacancy, but also boost the recombination of solute atoms and vacancy ${ }^{[19]}$. Moreover, it is beneficial to the decrease of vacancy diffusion activation energy, and further accelerate the diffusion of solute atoms ${ }^{[12]}$. Prior to the temperature declines until below Ae3 point, $\mathrm{NbCN}$ nucleation points increase in huge amount and precipitate under the action of electropulsing, and form a large number of fine NbCN particles. After the temperature declines until below Ae3 point, these fine second-phase particles provide a huge amount of nuclear cores for ferrite nucleation. At the same time, electropulsing also reduces the nucleation potential barrier of ferrite. Under the combined action of these two factors, nucleation of ferrite precipitates in huge amount inside austenite grain and distribute in dispersive state, and effectively restrains the formation of pro-eutectoid ferrite film at austenite grain boundary.

\section{Conclusions}

(1) Electropulsing has significant impact on austenite $\rightarrow$ ferrite phase transition of low carbon steel and low carbon $\mathrm{Nb}$-containing steel, and improves the nucleation rate of ferrite inside austenite grain.

(2) Electropulsing boosts the nucleation and precipitation of $\mathrm{NbCN}$ in low carbon $\mathrm{Nb}$-containing steel, the precipitation of $\mathrm{NbCN}$ particle in huge amount provides nucleation sites for austenite $\rightarrow$ ferrite phase transition, and improves the nucleation rate of ferrite inside austenite grain.

(3) The improvement of nucleation rate of ferrite inside austenite grain effectively restrains the formation of pro-eutectoid ferrite film at austenite grain boundary. 


\section{Acknowledgements}

This work was supported by the Anhui College Provincial Key Project for Natural Science Research(KJ2012Z037).

\section{References}

[1] L.H.Yang, J.L.Huang, B.Yin. HotWorking Technology, 2003.2,p.51-54

[2] H.Conrad. Structural Materials: Properties, Microstructure and Processing, 2000.A287,p.227-236

[3] L.Yang, Y.C Wang, et al. Materials Science Forum, Switzerland: Trans Tech Publications Ltd,2010.V654-656,p.464-471

[4] B.Malard, J .Pilch, P.Sittner et al. ACTA MATERIALIA,2011.59(4),p.1542-1556

[5] R.S. Qin, E.I. Samuel, A.Bhowmik. Journal of Materials Science, 2011.26(9) ,p.2838-2842

[6] E.I.Samuel,A.Bhowmik, R.S.Qin. Journal of Materials Research, 2010,25(6) ,p.1020-1024

[7] S.Tanaka, Y.Takemori, M.Tsushida, et al. Materials Science Forum, 2008.566,p.351-356

[8] L.J.He, J.G.Qi, J.Z.Wang, et al. TRANSACTIONS OF MATERIALS AND HEAT TREATMENT, 2007.28,p.38-40

[9] Q.C.Li,R.X.Li,QiJie Zhai, et al. Journal of Materials Processing Technology, 2009.209 (4) ,p.2015-2020

[10]Q.C.Li, R.Li, Q.J.Zhai, et al. Materials Chemistry and Physics, 2008.112(2) ,p.402-406

[11]W.P.Yu, R.S.Qin, K.M.Wu. Advanced Materials Research, 2011.146,p.1849-1854

[12]W.B.Liu, Y.H.Wen; N.Li, et al. Journal of Alloys and Compounds,2009.V472:591-594

[13]J.J.Wang, L.Zhou, Q.Li, et al. Journal of Iron and Steel Research, 2007,19 (5) ,p.49-53

[14]J.X.Chen. Book of chart and data for steel-making. Beijing: The Metallurgical Industry Press, 1984

[15]WY.Xia,Z.H.Zhu,Yong Gan. Iron and Steel, 2011,46(12),p.29-32

[16]Y.T.Wang. Research on Iron and Steel, 2008.36(3),p.14-16

[17]Z.H.Zhu. The Chinese Journal of Process Engineering, 2011.11(6) ,p.958-963

[18]Y.H.Xiao. JOURANL OF SHANGHAI UNIVERSITY OF ENGINEERING SCIENCE, 2005.19(1),p.12-14

[19] H. Conrad. Materials Science and Engineering, 2000,A287,p.276 -287. 